\title{
Optimistically biased economic growth forecasts and negatively skewed annual variation
}

\author{
Matthew G. Burgess ${ }^{\mathrm{a}, \mathrm{b}, \mathrm{c}, 1}$, Ryan E. Langendorf ${ }^{\mathrm{a}}$, Tara Ippolito $^{\mathrm{b}}$, \\ and Roger Pielke Jr. ${ }^{b}$ \\ ${ }^{a}$ Cooperative Institute for Research in Environmental Sciences, University of \\ Colorado Boulder, CO 80309 \\ ${ }^{\mathrm{b}}$ Environmental Studies Program, University of Colorado Boulder, CO 80303 \\ ${ }^{\mathrm{c}}$ Department of Economics, University of Colorado Boulder, CO 80309 \\ ${ }^{1}$ correspondence to: matthew.g.burgess@colorado.edu
}

January 6, 2021

\begin{abstract}
Authoritative economic growth forecasts are often optimistically biased. Negatively skewed variation-negative shocks being larger than positive shocks-could contribute to bias by making long-run average growth smaller than typical-year (median) growth. This positively biases forecasts based on typical years. We compare medians and means in real per-capita GDP growth across countries, regions, and time windows from 1820-2016. Over decadal periods, we find mean growth rates $<1 \% / y$ smaller than median growth rates in most countries and regions (median $0.23 \% / y$ across countries). Surprisingly, we find both large- and mediummagnitude shocks contribute to these differences, rather than only large 'black swan' events. We find negative skewness correlated with high levels and slow growth of per-capita GDP and population, and high per-capita GDP growth volatility, building on previous studies. We find negative skewness alone insufficient to explain recent growth over-projections by the International Monetary Fund (IMF) and the U.S. Congressional Budget Office $(\mathrm{CBO})$.
\end{abstract}

\section{Keywords}

growth, business cycle, recessions, COVID-19, climate change

\section{JEL Codes}

E30, E32, E37, O10, O11, O40, O44, O47, O57, Q01, Q56, Q57 


\section{Introduction}

Authoritative economic forecasts-such as International Monetary Fund (IMF) World Economic Outlook (WEO) (IMF, 2020) and the Congressional Budget Office (CBO) U.S. forecasts (CBO, 2020a)-are critical to multiple facets of research and policymaking, and are often positively biased, especially on longer-horizons ( $>3$ years ahead) (Timmermann, 2007; De Resende, 2014; CBO, 2019). Economic forecast biases can collaterally bias projections of other policy-relevant factors, such as public deficits (Blanchard \& Leigh, 2013; CBO, 2019) and greenhouse-gas emissions (Le Quéré et al., 2020; Burgess et al., 2021).

The COVID-19 pandemic illustrates one possible reason for positive economic forecast bias: large, unexpected shocks-by definition difficult to predict (Taleb, 2007)-are often negative. If negative shocks are larger than positive shocks, the distribution of economic growth rates is negatively skewed (also called left-skewed), making longrun average (mean) growth rates smaller than typical-year (median or mode) growth rates, and positively biasing forecasts based on typical years. Rational forecasters would project the median of their uncertainty as a point estimate if their objective was to minimize mean absolute forecast error; in this case, their average bias would equal the difference between mean and median if uncertainty was accurately estimated (Gu \& Wu, 2003; Gneiting, 2011). (In contrast, forecasting the mean of uncertainty minimizes mean squared error (Gneiting, 2011).) Negative skewness can also positively bias economic forecasts if tail risks are challenging or impossible to estimate accurately (e.g., Müller \& Watson (2016); Adrian et al. (2019)).

Several studies have found negative skewness in economic growth and related quantities. Bekaert \& Popov (2019) found negatively skewed economic growth-measured by the Fisher-Pearson coefficient of skewness (hereafter 'Pearson skewness')-widespread across a sample of 110 countries post-1960, with greater negative skewness being associated with greater volatility in richer countries. Popov (2014) found negatively skewed economic growth associated with financial openness in post-1970 developing countries. Salgado et al. (2019) found negatively skewed productivity, sales, and employment growth during recessions across fifty countries. Adrian et al. (2019) found left-tail risk was the predominant driver of U.S. growth volatility since the 1970s. Other studies have either documented business-cycle skewness (Diebold \& Rudebusch, 1990; Acemoglu \& Scott, 1994; Müller \& Watson, 2016), or predicted it in models (Zeira, 1994; Acemoglu \& Scott, 1997; Bekaert \& Engstrom, 2017). Gu \& Wu (2003) found corporate earnings are often negatively skewed, with implications for investment risk.

Here, we provide two contributions. First, we characterize patterns of skewness in the annual variation of real per-capita GDP growth, across 169 countries and seven regions since the Industrial Revolution (1820-2016) (data from Bolt et al. (2018); Roser (2020)). In contrast to previous studies (e.g., Bekaert \& Popov (2019)), we measure skewness as the difference between mean and median growth rates (either raw, or normalized to medium-to-long-term trends). This measure has a direct theoretical link to expected forecast bias when minimizing mean absolute error ( $\mathrm{Gu} \& \mathrm{Wu}, 2003$ ), and, as we show, is only moderately correlated with Pearson skewness in country-level growth data. Our research questions are: (i) How pervasive and large in magnitude is skewness, by this measure? (ii) How important are 'black-swan' (i.e. rare and major (Taleb, 2007)) events in driving overall skewness? (iii) How does skewness vary temporally and regionally? Second, we compare this measure of skewness to recent forecast errors by the IMF WEO (2004-2019) and the CBO (1982-2019), to explore links between skewness and biases. 
While our analysis has implications for macroeconomics, our intended target audience is broader, including all who use economic growth forecasts in their research. Many such researchers may not be aware of forecast biases or negatively skewed economic growth patterns. Relating differences between mean and median growth rates to forecast biases is also applicable to other types of forecasts ( $\mathrm{Gu} \& \mathrm{Wu}, 2003)$. Moreover, skewness likely biases forecasts in other contexts. For instance, Anderson et al. (2017) found negatively skewed population growth patterns likely cause underestimation of endangered species extinction risk.

\section{Measuring skewness}

We use a continuous measure of annual economic growth (see Appendix A for details regarding data processing). Per-capita GDP growth in year $t$ in country or region $i$, denoted $g_{i, t}$ is defined as:

$$
g_{i, t}=100\left[\ln \left(\text { p.c.GDP } P_{i, t}\right)-\ln \left(\text { p.c. } G D P_{i, t-1}\right)\right]
$$

Using a continuous measure makes the multi-year total growth rate equal to the sum of the annual growth rates, and multi-year average growth equal to the arithmetic mean of annual growth rates. We analyze real per-capita GDP growth in purchasingpower parity (PPP) units, except where otherwise indicated (e.g., in section 5).

In order to explore short-term deviations from longer-term trends, we normalize growth rates relative to 11-year moving medians. The normalized growth rate of country or region $i$ in year $t$, denoted $d_{i, t}$, is calculated as:

$$
d_{i, t}=g_{i, t}-\operatorname{med}\left(g_{i, t-5}, \ldots, g_{i, t+5}\right) .
$$

For instance, $d_{i, t}$ for 1995 is the growth rate in 1995 minus the median annual growth rate from 1990-2000. Our results are qualitatively robust to using alternate moving-window sizes ( 5 years and 21 years) as well as not normalizing, as we show in Appendix B.

\section{$3 \quad$ Patterns of skewness}

Fig. 1A shows the difference between mean and median $d_{i, t}$ for each country, calculated across all available data from 1820-2016 (Bolt et al., 2018; Roser, 2020). The longest time series in our analysis is 197 years (1820-2016; e.g., Denmark, Sweden, United Kingdom). The shortest is 24 years (1993-2016; United Arab Emirates). Roughly half of the countries (88/169) have data beginning between 1950-1952 and ending in 2016; and roughly one third $(58 / 169)$ have longer time series than this.

Mean $\left(d_{i, t}\right)-\operatorname{med}\left(d_{i, t}\right)<(>) 0$ implies negative (positive) skewness. Two-thirds of the countries $(108 / 169)$ in our dataset show negatively skewed growth-the rest positive (median $-0.23 \% / \mathrm{y})$. The absolute value of mean $\left(d_{i, t}\right)-\operatorname{med}\left(d_{i, t}\right)$ was less than 1 for most countries ( 85 out of 108 showing negative skewness; 57 out of 61 showing positive skewness). Many countries exhibiting positive skewness are in Africa or western Asia (Fig. 1C, Fig. 2B). These patterns are robust to: variations in moving-window size, not normalizing growth rates (Figs. B1-B5), and measuring skewness using Pearson skewness (Fig. B2). However, Pearson skewness is only moderately correlated with $\operatorname{Mean}\left(d_{i, t}\right)-\operatorname{med}\left(d_{i, t}\right)(0.43<r<0.58$, varying by moving-window size; Fig. B2). 

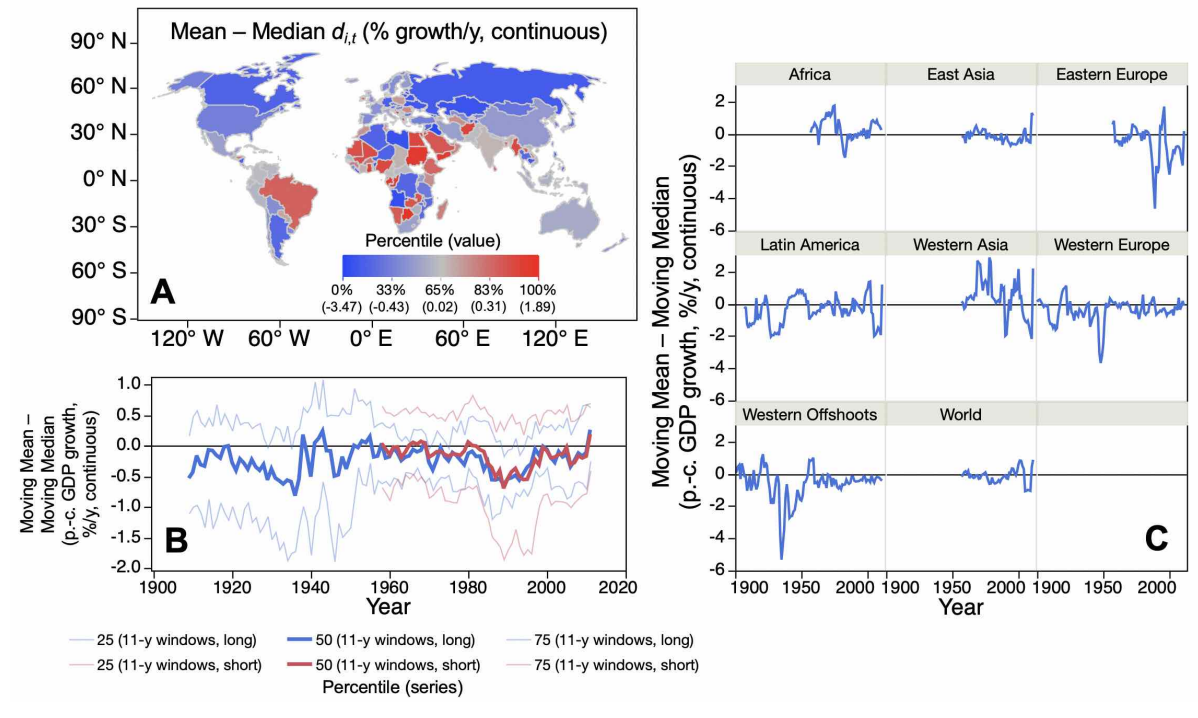

Figure 1: (A) Comparison of country-level mean and median normalized real per-capita GDP growth (PPP) growth rates $\left(d_{i, t}\right)$. (B) Time series of 25 th, 50 th and 75 th percentiles of moving mean - moving median per-capita GDP growth, across short (1952-2016) and long (1901-2016) balanced panels of countries. (C) Time series of moving mean - moving median per-capita GDP growth in each of seven regions and the world as a whole. Data from Bolt et al. (2018); Roser (2020).

Global patterns of skewness have been fairly stable since the early 1900s (data are too sparse to draw pre-1900 conclusions) (Fig. 1B). Fig. 1B shows trends of moving mean - moving median per-capita GDP growth (11-year windows) over time in two balanced panels (i.e. all countries included have data for all years)-one from 19012016 ("long", 38 countries-largely developed), the other from 1952-2016 ("short", 134 countries). Both time series show similar central tendencies-the 50th percentiles of moving mean - moving median per-capita GDP growth mostly vary between 0 and $-0.5 \% / y$, and show greater negative skewness just before World War II and during the fall of the Soviet Union (Fig. 1B,C). There is greater cross-country variation in skewness in the short panel and when using shorter moving windows (Fig. 1B,C, Figs. B3, B4).

Surprisingly, we find skewness is driven by both large and medium-sized (both rare and common) shocks, rather than being driven only by large 'black swan' (Taleb, $2007)$ events. To visualize this result, Fig. 2 compares mean $\left(d_{i, t}\right)-\operatorname{med}\left(d_{i, t}\right)$, across countries (Fig. 2A) and regions (Fig. 2B), using different fractions of the data, moving outward from the median (e.g., " $\%$ of distribution included" $=50 \%$, means that only the 25 th- 75 th percentile range, in $d_{i, t}$, is included). If skewness in economic growth was being driven solely by rare (once-in-a-decade or rarer) events, then we would expect to see the points in Fig. 2 cluster around zero until the percentage of the distribution included was large, at which point we would see an abrupt decrease (if skewness was negative). Instead, we mostly see smooth curves, often with one third or more of the distribution (i.e. one-in-three-year shocks) contributing to the skewness. Smaller shocks contribute more to skewness, on average, in regions (Fig. 2B) than countries (Fig. 2A), possibly because large shocks occurring in subsets of countries appear as 


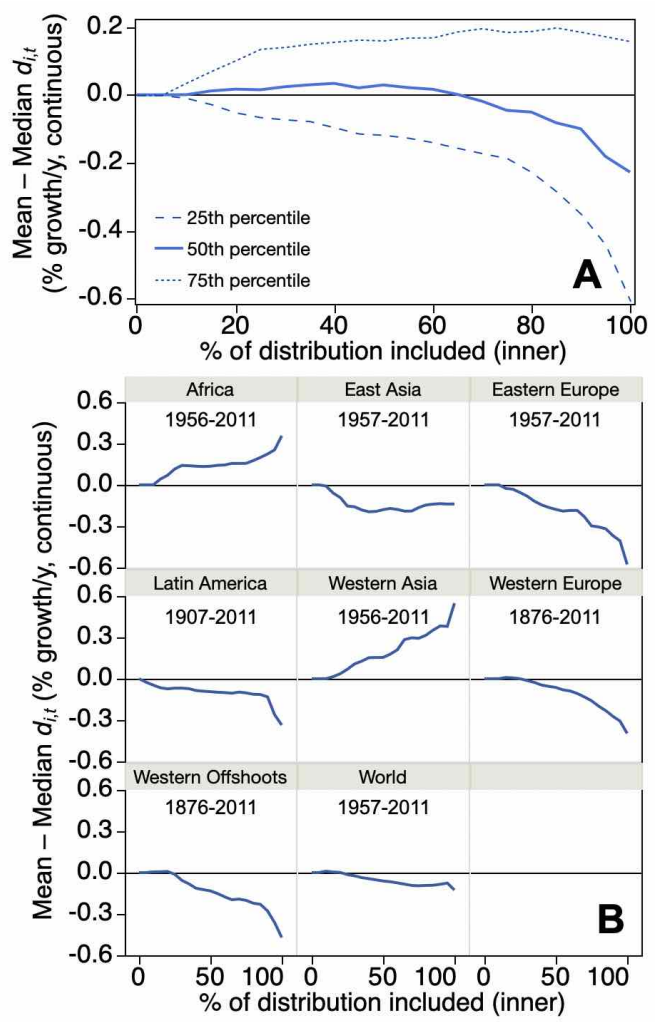

Figure 2: Skewness (measured as mean $\left.\left(d_{i, t}\right)-\operatorname{med}\left(d_{i, t}\right)\right)$ in different inner fractions of the $d_{i, t}$ distributions of countries (A) and regions (B). Panel A shows 25th-75th percentiles among the 169 countries (see Fig. B1 for full range).

small shocks regionally. These patterns are also robust to varying moving-window sizes (Figs. B1-B5).

In Fig. 3 and in Appendix B, we use cross-sectional and panel regressions to examine partial correlations between our measure of skewness $\left(\operatorname{mean}\left(d_{i, t}\right)-\operatorname{med}\left(d_{i, t}\right)\right)$ and: per-capita GDP levels and growth rates, population levels and growth rates, volatility (measured as the s.d. of per-capita GDP growth rates, following Bekaert \& Popov (2019)), and interactions between these variables. In contrast to Bekaert \& Popov (2019), we find a weakly negative cross-sectional correlation between skewness and volatility-a difference owing to additional countries and years included in our dataset with high volatility and negative skewness (e.g., Iraq, Lenanon, Libya, Liberia; the Arab Spring) (Fig. B6). This negative correlation is strengthened when controlling for other variables (Fig. 3, Tables B1, B2). We also find negative skewness associated with: larger population and per-capita GDP, and slower per-capita GDP growth and population growth (Fig. 3). We find significant interactions-consistently across alternate panel and cross-sectional model specifications-between: per-capita GDP growth and volatility (positive; i.e. volatility is associated with more positive skewness in faster-growing countries), and per-capita GDP growth and population (negative; greater per-capita GDP growth is associated with more positive skewness 

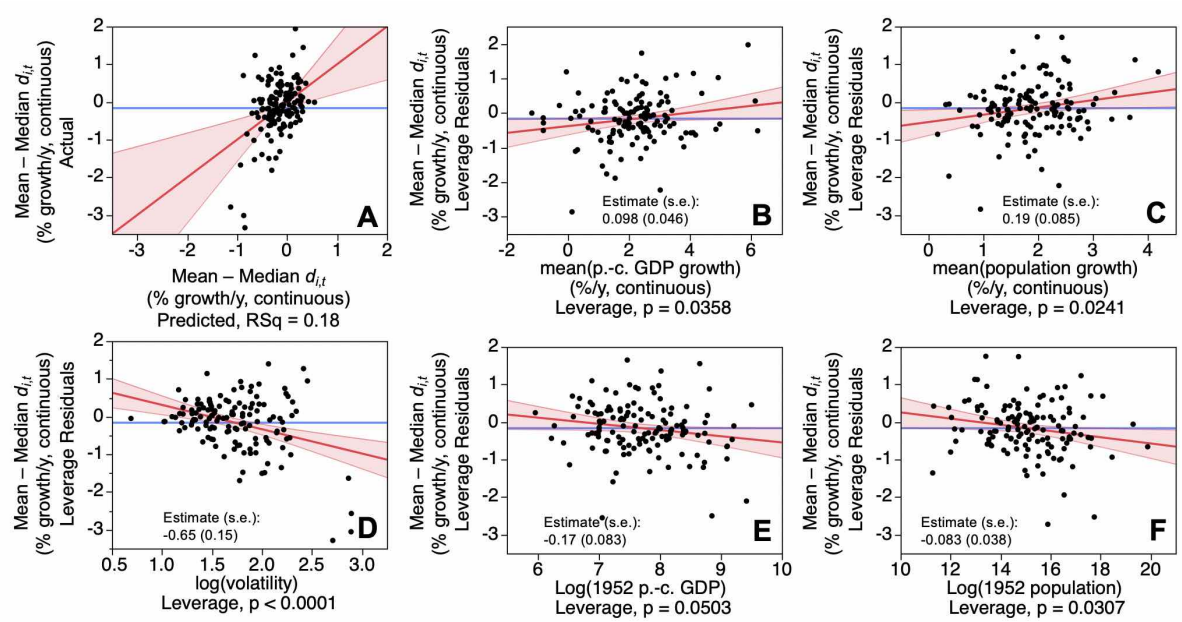

Figure 3: Cross-sectional analysis (leverage plots, from an OLS model) of partial correlations between mean - median $d_{i, t}$ (using 11-y windows) (our measure of skewness) and covariates, in the spirit of the analysis by Bekaert \& Popov (2019). Volatility here refers to the standard deviation of per-capita GDP growth across the time series. Only countries with annual data from 1952-2016 are included in this analysis $(n=134)$.

in smaller countries) (Tables B1, B2).

\section{Skewness and IMF forecast errors}

The IMF WEO economic forecasts vary in their methods across regional teams, using combinations of structural models (e.g. production functions), statistical analyses, and expert judgment (De Resende, 2014). They consider a range of factors, including policies, structural and business cycle conditions, and accounting identities between key variables (De Resende, 2014). Regional teams coordinate to ensure consistency, especially for short-term forecasts (1-2 years ahead) (De Resende, 2014). Mediumterm forecasts (3-5 years ahead) often assume GDP will converge to potential GDP (the maximum output an economy can produce without increasing inflation (OECD, 2017)). Previous assessments (Timmermann, 2007; De Resende, 2014) identified this assumption as contributing to optimistic forecast errors, along with forecasters' inabilities to predict recessions (Timmermann, 2007; De Resende, 2014), and optimistic bias in countries participating in IMF programs (De Resende, 2014) or receiving IMF credit (Aldenhoff, 2007). IMF forecast methods' heterogeneity complicates a priori assessments of whether they account for skewness, but poorly forecasting shocks could link skewness to bias.

Since the Great Recession of 2008-2009, the IMF WEO has over-projected growth globally and regionally (Fig. 4A). IMF forecasts were consistently more optimistic the farther ahead projections were (Fig. 4A, Fig. B7). In contrast, one-year-ahead IMF forecasts consistently under-projected per-capita GDP growth before the Great Recession (2004-2007) (projections multiple years ahead were not available pre-2008). We find similar patterns at the country level (Fig. B7).

IMF projections heavily influence scenarios used in climate change research, such 

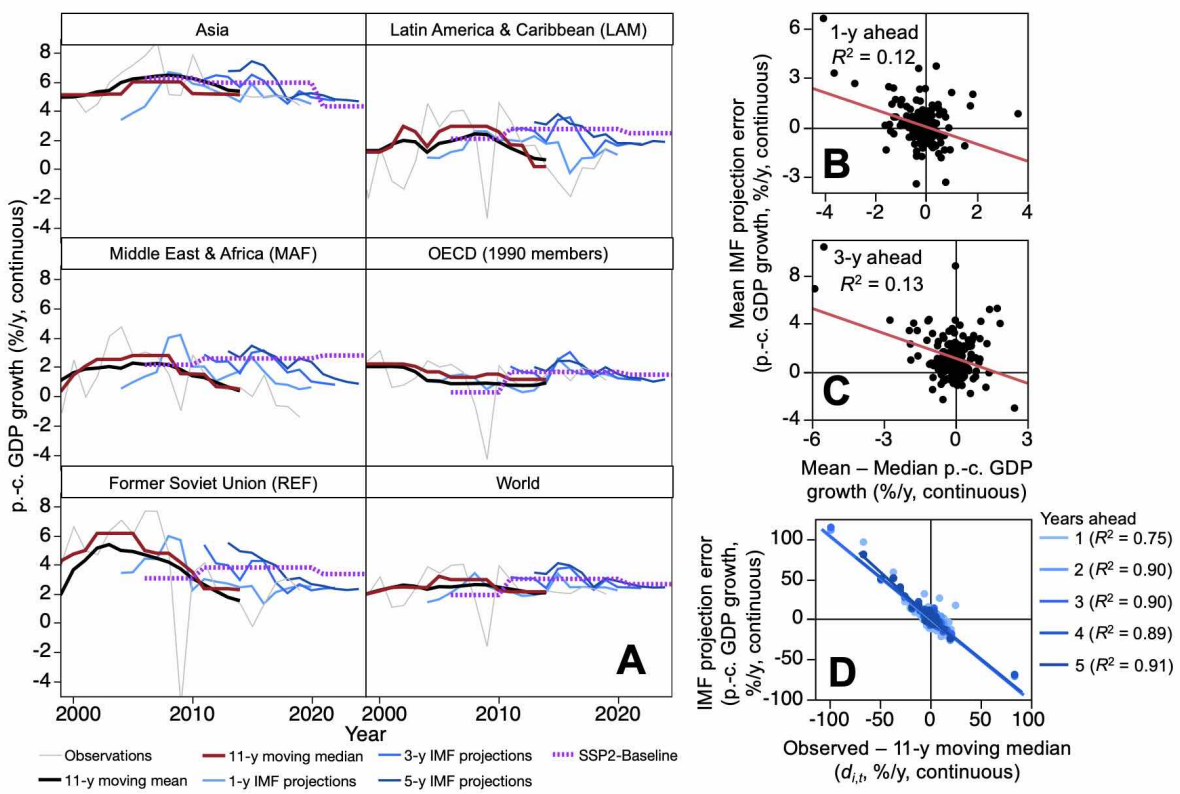

Figure 4: (A) Comparison of per-capita GDP growth rates: observed (light grey), 11-year moving mean (black) and median (red), and projected by the IMF World Economic Outlook (blue) and the "middle of the road" Shared Socioeconomic Pathway scenario (SSP2) (Dellink et al., 2017) (purple, dashed). We show only SSP2 (among the SSPs) because economic growth forecasts of all SSPs are similar over this time period, due to their basis in IMF and OECD forecasts (Dellink et al., 2017; Riahi et al., 2017). Projections are shown according to the year of the projection (e.g. a 5-y projection for 2015 is 2015 growth projected in 2010). Panels B and C show correlations between mean IMF projection errors in per-capita GDP growth (2004-2019 in B; 2011-2019 in C) and the difference between mean and median per-capita GDP growth over the same period. Each point represents one country ( $n=164$ in $\mathrm{B}, n=175$ in C). OLS fits, including an intercept, are shown (red lines). Negative slopes are statistically significant, with $p<0.001$, in both panels. Positive intercept is statistically significant in panel C only, with $p<0.001$. Panel D shows correlation between $d_{i, t}$ (observed growth - 11-y moving median growth) and IMF growth projection errors, on different forecast horizons. Lines represent OLS fits. Negative slopes are statistically significant $(p<0.001)$ in all forecast horizons and have magnitudes very close to -1 (Figs. B8, B9, Table B3). The intercept was negative on a 1-y horizon, positive on all other horizons, and statistically significant $(p<0.001)$ in all horizons.

as the Shared Socioeconomic Pathway (SSP) scenarios (Dellink et al., 2017; Riahi et al., 2017). Fig. 4A shows how projected growth in the "middle of the road" SSP scenario (SSP2) has overshot observed growth by magnitudes similar to IMF mediumterm forecasts. Other scenarios assume similar growth rates pre-2020 (Dellink et al., 2017), and have consequently over-projected growth by similar magnitudes (Burgess et al., 2021).

The strongest evidence for a role of skewness in IMF forecast errors comes from the fact that the difference between observed and moving median growth (i.e. $d_{i, t}$ explains most of the variance $\left(R^{2} \geq 0.75\right)$ in IMF forecast errors, in each forecast horizon, with a nearly 1:1 correlation between the magnitudes of $d_{i, t}$ and the forecast error. (Fig. 4D). This suggests-not surprisingly-that IMF forecast errors are strongly correlated with the magnitude of shocks-a correlation with potential to introduce longrun bias via skewness. Indeed, we see a modest negative correlation between mean 
forecast errors and skewness across countries $\left(R^{2}=0.13\right.$ on a three-year horizon) (Fig. $4 \mathrm{~B}, \mathrm{C})$. This correlation is slightly weaker when using Pearson skewness instead of the difference between mean and median growth (Fig. B10).

However, we also see clear evidence that skewness is insufficient to explain the IMF's forecast errors. The IMF's post-2009 medium-term forecast errors (3-5 years ahead) are substantially larger than can be solely explained by negatively skewed growth variation. Their projections consistently exceed moving medians in all regions (Fig. 4A), with similar country-level patterns (Fig. 4C,D, Fig. B7). Across countries, the 50th percentile of mean (across years) medium-term forecast errors ranged from $0.91 \% / y$ (3 years ahead) to $1.33 \% / y$ ( 5 years ahead)-much larger in absolute value than both the typical range of mean $\left.\left(d_{i, t}\right)-\operatorname{med}\left(d_{i, t}\right)\right)(-0.5 \% / \mathrm{y}$ to $0 \% / \mathrm{y})$ and the 50 th percentile of mean - median per-capita GDP growth from 2011-2019 (the years corresponding to medium-term projections) $(-0.056 \% / y)$. We can also see evidence for effects on forecast errors, additional to skewness, in statistically significant and positive intercept terms-on two-to-five-year forecast horizons-in OLS regressions of forecast error on $d_{i, t}$ (Fig. 4). The fact that other factors beyond skewness contribute to forecast errors is not surprising, given the other sources of error noted by previous studies (Aldenhoff, 2007; Timmermann, 2007; De Resende, 2014).

We find a slight time trend in IMF's forecast errors. One-year-ahead forecasts became more optimistic over time-before and after the Great Recession (Figs. B8, B9)-while 2-5-year-ahead forecasts became slightly less optimistic over time (Table B3).

\section{Skewness and CBO forecast errors}

The CBO's U.S. economic growth forecasts also use a combination of statistical and structural modeling (CBO, 2019, 2020b), and aim to account for possible negative skewness in two ways. First, they report forecasts which are means (rather than the median or mode) of estimated outcome distributions (CBO, 2020b). However, this only accounts for skewness in practice if the outcome distributions-especially downside risks-are accurately estimated. Second, the CBO assumes a persistent negative output gap (i.e. difference between actual and potential GDP) of $0.5 \%$ based on historical output gaps between the 1950s and the 2000s (CBO, 2020b). This would account for negative skewness in growth to the extent that average output gaps measure past skewness and predict future skewness. The CBO identifies the following factors as contributing to forecast errors (CBO, 2019): unpredictability of growth in and around recessions, shifts in labor productivity trends (e.g., increasing during the late '90s, decreasing post-2006), changes in oil prices, declining interest rates, declining labor compensation relative to GDP, and data revisions. Of these, recessions are most related to negatively skewed growth patterns.

We see two patterns in CBO forecast errors (1980s-2010s) which are similar to the IMF. First, much of the error owes to failing to project or under-projecting shocks (Figs. 5D, B11, Table B4), which may suggest that negative skewness contributes to positive bias (though a cross-sectional comparison-analogous to Fig. 4B,C-cannot be done in the $\mathrm{CBO}$ data, as they come from a single country). As with the IMF's errors, CBO's growth projection errors had a nearly 1:1 correlation with the difference between observed growth and its 11-y moving median, $d_{i, t}$ (slope of this relationship was between -0.85 and -0.92 in 2 -y-to 6 -y-ahead forecasts; Fig. 5D).

Second, medium-term (3-6-year) forecasts are more optimistic than short-term 

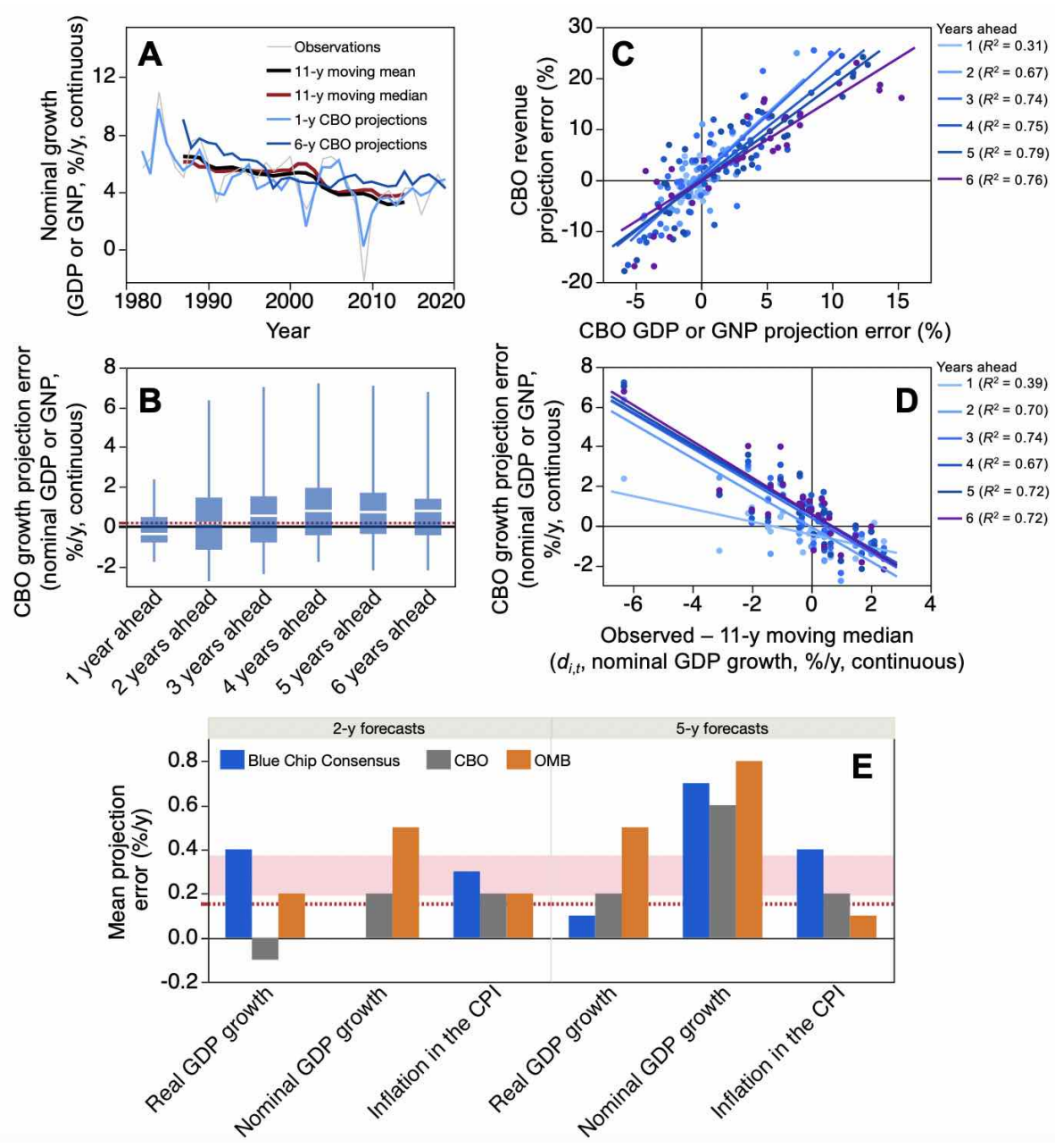

Figure 5: U.S. CBO (CBO, 2020a) projections of U.S. economic growth (nominal GDP or GNP) and federal revenues, compared to observations, from 1982-2019. Panel A compares growth rates: observed (light grey), 11-year moving mean (black) and median (red), and CBO projections (blue). Projections are again shown according to the year projected (e.g. a 6-y projection for 2015 indicates 2015 growth projected in 2009). Panel B shows nominal growth projection errors on various timeframes. Boxes represent 25th-75th percentile (among years); whiskers represent min to max. The red dashed line represents the median - mean nominal GDP growth from 1982-2019. The (very narrow) pink shaded region represents the range of $\operatorname{med}\left(d_{i, t}\right)-\operatorname{mean}\left(d_{i, t}\right)$ values (using nominal growth instead of real per-capita growth) using 5-y, 11-y, and 21-y windows. Panel C compares projection errors in nominal GDP or GNP to projection errors in federal revenue, both as a percentage of the eventually-observed value. Panel D compares growth projection errors to $d_{i, t}$ values (analogous to Fig. 4D). Lines in C and D indicate linear OLS fits $(p<0.001$ for all slopes in D; $p<0.01$ for all slopes except 1-y ahead in C; $p<0.05$ for all intercepts in D except 2-y ahead (and for none in $\mathrm{C})$ ). Panel E shows mean GDP growth and inflation (in the consumer price index, CPI) projection errors from the $\mathrm{CBO}$, the OMB, and the Blue Chip consensus, from the 1980s to the mid-2010s (see table 1 in CBO (2019)). The red dashed line represents the median - mean real GDP growth from 1979-2016. The pink shaded region represents the range of $\operatorname{med}\left(d_{i, t}\right)-$ mean $\left(d_{i, t}\right)$ (using real GDP growth instead of real per-capita GDP growth) using 5-y, 11-y, and 21-y windows. 
(1-2-year) forecasts (Fig. 5A,B,D,E). Short-term growth forecasts have not been consistently optimistic (Fig. 5A,E, B11; CBO (2019, 2020a)), whereas medium-term forecasts have been optimistic in all periods except the late 1990s (dot-com boom) and the early 2000s (housing boom) (Fig. 5A,B). Other forecasts of U.S. growth show similar patterns-Fig. 5E shows CBO's comparison of their own forecast errors to those of the Office of Management and Budget (OMB) and the Blue Chip consensus (CBO, 2019).

Although skewness may play a role in CBO forecast errors, we find evidencesimilarly to the IMF case-that skewness is insufficient to explain the errors, and thus additional factors must also contribute (see CBO (2019)). CBO's medium-term nominal growth forecast errors (50th percentiles range from $0.57 \% / \mathrm{y}$ in 3 -year forecasts to $0.81 \% / y$ in 6 -year forecasts) are larger in absolute value than differences between mean and median nominal growth rates and $d_{i, t}$ values $(-0.16 \% / \mathrm{y}$, across the time series) (Fig. 5A,B). Indeed, we find positive and significant intercept terms in OLS regressions of forecast error on $d_{i, t}$ (Fig. $5 \mathrm{D}$ ).

Some of the CBO's medium-term over-projection of nominal growth owes to overprojecting inflation (Fig. 5E), which is not strongly correlated with growth overprojections (see figures 3 and 5 in CBO (2019)), and thus not clearly linked to skewness. CBO's 5-year real GDP growth forecast errors are similar in magnitude (mean 0.2\%/y $(\mathrm{CBO}, 2019))$ to differences between mean and median real growth rates or $d_{i, t}$ values (Fig. 5E). Interestingly, OMB's optimistic biases have been larger than CBO's by a magnitude similar to our measures of negative skewness (mean - median growth). This may be noteworthy given CBO's assumptions intending to account for negative skewness-namely, forecasting the mean of estimated uncertainty (e.g., the Federal Reserve uses the mode instead (CBO, 2019)), and assuming persistent output gaps (CBO, 2020c). However, the fact that CBO's short-term forecasts have not been systematically optimistic may suggest other factors besides skewness play key roles in optimistic medium-term bias (e.g., recently declining productivity growth; see Gordon (2016); CBO (2019)).

Growth forecast errors have important fiscal implications (e.g., Blanchard \& Leigh (2013)). For instance, as we show in Fig. 5C, CBO's forecast errors of U.S. GDP have been strongly correlated with their forecast errors of federal revenue-each 1\% GDP forecast over-(under-) projection approximately corresponds to a $2 \%$ revenue forecast over-(under-) projection. Before the onset of the COVID-19 crisis, the CBO forecasted U.S. federal debt would reach $180 \%$ of GDP by 2050 (CBO, 2020a), but it could be higher if GDP remains below its currently forecasted trajectory (Gordon (2016) also notes this possibility).

\section{Discussion}

The COVID-19 crisis has drawn attention to negatively skewed economic growth variation-negative shocks often having larger magnitudes than positive shocks. We explored regional and temporal patterns and extent of negative skewness in per-capita GDP growth since the Industrial Revolution (1820-2016), and its possible links to optimistically biased forecasts by authoritative sources widely used in economic and environmental research and policy: the IMF, the SSPs, and the CBO.

We used an intuitive measure of economic growth skewness-comparing average growth rates with typical (median) growth rates. This measure provides a theoretically grounded link between skewness and potential forecast bias: Rational forecasters 
minimizing mean absolute forecast error and accurately estimating the outcome distribution would forecast the median ( $\mathrm{Gu} \& \mathrm{Wu}, 2003$; Gneiting, 2011) and thus be biased by our measure of skewness (mean - median) on average.

We found negatively skewed economic growth variation is widespread but not universal (Fig. 1), and, surprisingly, is driven by both rare and common (e.g., one-inthree-year) shocks (Fig. 2), rather than being driven predominantly by rare shocks (black swans).

Our measure of negative skewness is correlated with: slow average per-capita GDP and population growth, high per-capita GDP growth volatility, and high per-capita GDP and population, within and across countries (Figs. 3, B6, Tables B1, B2). This is consistent with the finding of Bekaert \& Popov (2019) that volatility is associated with more negative skewness in richer countries (and their related hypotheses), even though we did not find the positive correlation they report in cross-sectional data (Fig. B6). Analogously, larger companies have more negatively skewed returns than smaller companies (Harvey \& Siddique, 2000). These patterns are intuitive: larger entities have larger left-tail risk (farther to fall) than right-tail risk (e.g., because of diminishing returns).

Our results were qualitatively consistent when using raw growth rates or normalizing to 5-, 11-, or 21-year moving medians. Our measures of skewness within countries or regions were typically also quantitatively similar in individual regions or countries, except in cases with longer-period fluctuations in growth (e.g., several consecutive years of rapid decline followed by several consecutive years of rapid growth) which contributed to skewness in raw growth but not normalized growth, $d_{i, t}$ (e.g., see Western Asia in Fig. B5). Comparing skewness across different dynamic frequencies was beyond the scope of our analysis but merits further study (e.g., Müller \& Watson (2016)).

Our analysis suggests that negatively skewed growth plausibly contributes to optimistic biases in IMF and CBO projections, but is insufficient to explain these biases alone, and thus other factors must also contribute.

We find evidence for a role of negative skewness in bias in: (i) the strong correlation between forecast errors and deviations from moving median growth, in both the IMF (Fig. 4D) and CBO (Fig. 5D) data; and (ii) the modest negative correlation between mean - median growth (i.e. skewness) and the mean IMF projection error across countries (Fig. 4B,C). The fact that the OMB's optimistic forecast bias has been greater than the CBO's may also be suggestive of a role of skewness in forecast bias, given that the CBO takes additional steps to account for skewness (CBO, 2019, 2020c). However, this hypothesis merits further scrutiny.

Other factors also contribute to these optimistic forecast biases. In our analysis, we see this in medium-term (3-6-year) biases being larger than differences between mean and median growth rates (Fig. 4A,C, Fig. 5A,B), and in larger optimistic biases in medium-term forecasts than in short-term (1-2-year) forecasts. For example, GDP failing to converge to potential GDP over the medium term could be partly caused by skewness, but could also be caused by inaccurate estimates of potential GDP (De Resende, 2014), or potential GDP being more of an upper bound than an average throughout the business cycle (i.e., the 'Plucking model' (Friedman, 1993)-see Dupraz et al. (2019)).

Political factors may also contribute to optimistic growth forecast biases. IMF forecasters may have incentive to forecast large effects of IMF programs (De Resende, 2014), or assume continuing progress towards international development goals (e.g., as the SSPs assume (Riahi et al., 2017)), including high sustained economic growth 
in developing regions and per-capita GDP convergence between rich and poor countries. Incumbent national governments may benefit politically from optimistic economic growth projections (higher growth benefits incumbents (Feng, 1997)). This may contribute to the OMB (managed by the White House) having greater optimistic forecast bias than the CBO (CBO, 2019) (Krause \& Corder (2007) found analogous patterns). Fear of self-fulfilling recession predictions may also positively bias forecasters (De Resende, 2014).

Optimistically biased growth forecasts may also signal that the economic headwinds projected by most economists to slow 21st-century growth in most regions (e.g., see ranges of projections in Christensen et al. (2018); Dellink et al. (2017); Müller et al. (2019); Startz (2020)) are more severe than some anticipated. Headwinds include aging populations, debt, some drivers of productivity growth (e.g. education) naturally plateauing, and middle-income countries completing their rapid industrializations (see, e.g. Gordon (2016)). Some scholars foresee innovation slowdowns (relative to the 20th century) (Gordon, 2016), climate change (Woodard et al., 2019), and/or accelerating declines in birth rates (Bricker \& Ibbitson, 2019; Jones, 2020; Vollset et al., 2020) further depressing 21st-century growth. The IMF's and CBO's successive downward revisions of post-2008 growth forecasts (Fig. 4, 5) are consistent with this narrative, and with the CBO's finding that declining productivity growth has contributed to its forecast errors (CBO, 2019). However, this hypothesis also merits further scrutiny.

Finally, economic forecasting is simply difficult, especially on longer horizons, as small errors and uncertainties compound (Morgan, 2018). The economy is a highly complex system, with uncertainties in the future evolution of each element (e.g. technology, trade, inequality, policies, the financial system). This may be why, for instance, Rossi \& Sekhposyan (2010) found that many traditional economic indicators (e.g., price indices, unemployment, Federal Reserve interest rates) have lost much of their predictive power regarding output growth since the mid 1980s. On the other hand, finding systematic biases in forecasts-such as those discussed here-might be conducive to improving them. Systematic bias may be easier to correct for than imprecision. One simple approach to reducing mean bias would be to materially reward forecasters based on success at minimizing squared errors (Gneiting, 2011).

Regardless of the reasons, positive biases in authoritative economic forecasts have important implications for research and policy. For instance, fiscal outlooks using optimistic economic forecasts are likely also optimistic (Fig. 5C)-at a time when public debt outlooks concern many economists (e.g., Reinhart et al. (2012); but see also Blanchard (2019)), and large-scale investments in infrastructure are needed to combat climate change. In climate change research, over-projections of economic growth might lead to overly pessimistic projections of 21st-century emissions (Burgess et al., 2021), but overly optimistic outlooks regarding other climate- and growth-adjacent societal challenges (e.g., adaptive capacity, social cohesion, conflict, inequality, and fiscal feasibility of large-scale public investments). These considerations will magnify if growth pessimists (e.g., Gordon (2016), and some macroeconomists surveyed by Christensen et al. (2018)) turn out to be right about the imminence and severity of coming worldwide economic slowdowns. Notably, the assumptions of the SSP3 scenario ('regional rivalry')-which imagines a world with relatively low trade and global cooperation (Riahi et al., 2017)-seem consistent with the aftermath of the COVID-19 pandemic, which is likely to reduce near-term trade as countries place greater emphasis on secure domestic supply chains (Baldwin \& di Mauro, 2020; Maliszewska et al., 2020; Ranald et al., 2020). The possibilities of slowing growth and magnifying related social and fiscal challenges highlight the need for institutions to consider and be robust 
to economic stagnation.

Lastly, the fact that negatively skewed growth is both widespread and caused by both common and rare shocks underscores the need for economic and fiscal planners to build resilience and left-tail risk into their policies and outlooks. Indeed, left-tail risk is an important consideration in a much wider range of policy issues (Taleb, 2007), perhaps especially those related to the environment and sustainability (e.g., Anderson et al. (2017); Weitzman (2009)).

\section{Acknowledgements}

We thank Akhil Rao and anonymous reviewers for helpful comments on a previous draft. This work was funded by the University of Colorado Boulder. The authors declare no competing interests.

\section{References}

Acemoglu, D., \& Scott, A. (1994). Asymmetries in the cyclical behaviour of uk labour markets. The Economic Journal, 104(427), 1303-1323.

Acemoglu, D., \& Scott, A. (1997). Asymmetric business cycles: Theory and time-series evidence. Journal of Monetary Economics, 40(3), 501-533.

Adrian, T., Boyarchenko, N., \& Giannone, D. (2019). Vulnerable growth. American Economic Review, 109(4), 1263-89.

Aldenhoff, F.-O. (2007). Are economic forecasts of the international monetary fund politically biased? a public choice analysis. The Review of International Organizations, 2(3), 239-260.

Anderson, S. C., Branch, T. A., Cooper, A. B., \& Dulvy, N. K. (2017). Black-swan events in animal populations. Proceedings of the National Academy of Sciences, $114(12), 3252-3257$.

Baldwin, R., \& di Mauro, B. W. (2020). Economics in the time of covid-19. A VoxEU. org Book, Centre for Economic Policy Research, London. Accessed, 26.

Bekaert, G., \& Engstrom, E. (2017). Asset return dynamics under habits and bad environment-good environment fundamentals. Journal of Political Economy, $125(3), 713-760$.

Bekaert, G., \& Popov, A. (2019). On the link between the volatility and skewness of growth. IMF Economic Review, 67(4), 746-790.

Blanchard, O. (2019). Public debt and low interest rates. American Economic Review, $109(4), 1197-1229$.

Blanchard, O. J., \& Leigh, D. (2013). Growth forecast errors and fiscal multipliers. American Economic Review, 103(3), 117-20.

Bolt, J., Inklaar, R., de Jong, H., \& Van Zanden, J. L. (2018). Rebasing 'maddison': new income comparisons and the shape of long-run economic development. $G G D C$ Research Memorandum, 174. 
Bricker, D., \& Ibbitson, J. (2019). Empty planet: the shock of global population decline. Hachette UK.

Burgess, M. G., Ritchie, J., Shapland, J., \& Pielke Jr, R. (2021). Ipcc baseline scenarios have over-projected co2 emissions and economic growth. Environmental Research Letters, 16(1), 014016.

CBO (2019). Cbo's economic forecasting record: 2019 update. Tech. rep., Congress of the United States.

CBO (2020a). Budget and economic data.

URL https://www.cbo.gov/data/budget-economic-data\#7

CBO (2020b). The budget and economic outlook: 2020 to 2030. Tech. rep., Congress of the United States.

CBO (2020c). Interim economic projections for 2020 and 2021. Tech. rep., Congress of the United States.

Christensen, P., Gillingham, K., \& Nordhaus, W. (2018). Uncertainty in forecasts of long-run economic growth. Proceedings of the National Academy of Sciences, $115(21), 5409-5414$.

De Resende, C. (2014). An assessment of imf medium-term forecasts of gdp growth. IEO Background Paper No. BP/14/01 (Washington: Independent Evaluation Office of the IMF).

Dellink, R., Chateau, J., Lanzi, E., \& Magné, B. (2017). Long-term economic growth projections in the shared socioeconomic pathways. Global Environmental Change, 42, 200-214.

Diebold, F. X., \& Rudebusch, G. D. (1990). A nonparametric investigation of duration dependence in the american business cycle. Journal of Political Economy, 98(3), 596-616.

Dupraz, S., Nakamura, E., \& Steinsson, J. (2019). A plucking model of business cycles. Tech. rep., National Bureau of Economic Research.

Feng, Y. (1997). Democracy, political stability and economic growth. British Journal of Political Science, 27(3), 391-418.

Friedman, M. (1993). The "plucking model" of business fluctuations revisited. Economic Inquiry, 31(2), 171-177.

Gneiting, T. (2011). Making and evaluating point forecasts. Journal of the American Statistical Association, 106(494), 746-762.

Gordon, R. J. (2016). The rise and fall of American growth: The US standard of living since the civil war, vol. 70. Princeton University Press.

Gu, Z., \& Wu, J. S. (2003). Earnings skewness and analyst forecast bias. Journal of Accounting and Economics, 35(1), 5-29.

Harvey, C. R., \& Siddique, A. (2000). Conditional skewness in asset pricing tests. The Journal of finance, 55(3), 1263-1295. 
IMF (2020). World economic outlook databases.

URL https://www.imf.org/en/Publications/SPROLLs/

world-economic-outlook-databases\#sort=\%40imfdate\%20descending

International Institute for Applied Systems Analysis (IIASA) (2018). Ssp public database version 2.0 .

URL https://tntcat.iiasa.ac.at/SspDb/dsd?Action=htmlpage\&page=about

Jones, C. I. (2020). The end of economic growth? unintended consequences of a declining population. Tech. rep., National Bureau of Economic Research.

Klein Goldewijk, K. (2007). History database of the global environment (hyde). Netherlands Environmental Assessment Agency.

Krause, G. A., \& Corder, J. K. (2007). Explaining bureaucratic optimism: Theory and evidence from us executive agency macroeconomic forecasts. American Political Science Review, (pp. 129-142).

Le Quéré, C., Jackson, R. B., Jones, M. W., Smith, A. J., Abernethy, S., Andrew, R. M., De-Gol, A. J., Willis, D. R., Shan, Y., Canadell, J. G., et al. (2020). Temporary reduction in daily global co 2 emissions during the covid-19 forced confinement. Nature Climate Change, (pp. 1-7).

Maliszewska, M., Mattoo, A., \& Van Der Mensbrugghe, D. (2020). The potential impact of covid-19 on gdp and trade: A preliminary assessment.

Max Roser, H. R., \& Ortiz-Ospina, E. (2019). World population growth. Our World in Data. Https://ourworldindata.org/world-population-growth.

Morgan, M. G. (2018). Uncertainty in long-run forecasts of quantities such as per capita gross domestic product. Proceedings of the National Academy of Sciences, $115(21), 5314-5316$.

Müller, U. K., Stock, J. H., \& Watson, M. W. (2019). An econometric model of international long-run growth dynamics. Tech. rep., National Bureau of Economic Research.

Müller, U. K., \& Watson, M. W. (2016). Measuring uncertainty about long-run predictions. Review of Economic Studies, 83(4), 1711-1740.

OECD (2017). Sources Methods of the OECD Economic Outlook. URL http://www. oecd.org/economy/outlook/sources-and-methods.htm

Popov, A. (2014). Credit constraints, equity market liberalization, and growth rate asymmetry. Journal of Development Economics, 107, 202-214.

Ranald, P., et al. (2020). Covid-19 pandemic slows global trade and exposes flaws in neoliberal trade policy. Journal of Australian Political Economy, The, (85), 108.

Reinhart, C. M., Reinhart, V. R., \& Rogoff, K. S. (2012). Public debt overhangs: advanced-economy episodes since 1800. Journal of Economic Perspectives, 26(3), $69-86$. 
Riahi, K., Van Vuuren, D. P., Kriegler, E., Edmonds, J., O’neill, B. C., Fujimori, S., Bauer, N., Calvin, K., Dellink, R., Fricko, O., et al. (2017). The shared socioeconomic pathways and their energy, land use, and greenhouse gas emissions implications: an overview. Global Environmental Change, 42, 153-168.

Roser, M. (2020). Economic growth. Our World in Data. Https://ourworldindata.org/economic-growth.

Rossi, B., \& Sekhposyan, T. (2010). Have economic models' forecasting performance for us output growth and inflation changed over time, and when? International Journal of Forecasting, 26(4), 808-835.

Salgado, S., Guvenen, F., \& Bloom, N. (2019). Skewed business cycles. Tech. rep., National Bureau of Economic Research.

Startz, R. (2020). The next hundred years of growth and convergence. Journal of Applied Econometrics, 35(1), 99-113.

Taleb, N. N. (2007). The black swan: The impact of the highly improbable, vol. 2. Random house.

Timmermann, A. (2007). An evaluation of the world economic outlook forecasts. IMF Staff Papers, 54(1), 1-33.

United Nations Population Division (2019 (accessed June 19, 2020)). World population prospects 2019 .

URL https://population.un.org/wpp/

Vollset, S. E., Goren, E., Yuan, C.-W., Cao, J., Smith, A. E., Hsiao, T., Bisignano, C., Azhar, G. S., Castro, E., Chalek, J., et al. (2020). Fertility, mortality, migration, and population scenarios for 195 countries and territories from 2017 to 2100: a forecasting analysis for the global burden of disease study. The Lancet, 396 (10258), $1285-1306$

Weitzman, M. L. (2009). On modeling and interpreting the economics of catastrophic climate change. The Review of Economics and Statistics, 91(1), 1-19.

Woodard, D. L., Davis, S. J., \& Randerson, J. T. (2019). Economic carbon cycle feedbacks may offset additional warming from natural feedbacks. Proceedings of the National Academy of Sciences, 116(3), 759-764.

Zeira, J. (1994). Informational cycles. The Review of Economic Studies, 61(1), 31-44. 


\section{Appendices}

\section{Appendix A: Data description}

Our main analysis uses real per-capita GDP data (in units of 2011 USD purchasing power parity, PPP), at the country level, from the Maddison Project (Bolt et al., 2018) via Roser (2020). We supplement these with population data from the UN (United Nations Population Division, 2019 (accessed June 19, 2020) and HYDE Database (Klein Goldewijk, 2007), via Max Roser \& Ortiz-Ospina (2019). For Figs. 1A,C, 2, $\mathrm{B} 1, \mathrm{~B} 2, \mathrm{~B} 3 \mathrm{~B}, \mathrm{~B} 4 \mathrm{~B}, \mathrm{~B} 5$, and B6B, we include all annual data from 1820-meaning some countries have longer time series. In Figs. 1B, 3, B3A, B4A, B6A, and Tables $\mathrm{B} 1$ and $\mathrm{B} 2$, we use balanced panels (i.e. only include countries having data in all years between the specified time periods), with time periods indicated.

For our comparisons to IMF projections, we obtain country-level projections from the historical archive of IMF World Economic Outlook Databases (WEO) from 2003 to 2019 (IMF, 2020). We use the latest forecasts from each year when multiple are available, and we exclude older databases (2000-2002 are available) due to the relatively small number of countries included in these earlier databases. We calculate real per-capita GDP growth (in PPP units) using equation [1], when using real per-capita GDP (PPP) values either directly given in the WEO reports or calculated from other data series (e.g., GDP and population). We use country-level data in Figs. 4B,C,D, B7-B10 and Table B3. We aggregate country-level data to IPCC regions in Fig. 4A, using the region definitions provided by IIASA (International Institute for Applied Systems Analysis (IIASA), 2018). SSP2 projections shown in Fig. 4A are visualized using the procedure described in Burgess et al. (2021), using annual GDP and population projections from the SSP database (International Institute for Applied Systems Analysis (IIASA) (2018); described in Dellink et al. (2017); Riahi et al. (2017)).

For our comparisons of U.S. growth to CBO projections (Figs. 5, B11, Table B4), we use growth and projection data, from 1982-2019, publicly available from the CBO (CBO, 2020a). We use nominal GDP (or GNP, pre-1992) growth (current USD) in this analysis-rather than real per-capita GDP growth-because CBO (CBO, 2020a) corrects for effects of new policies, enacted after the forecast, in its reporting of forecast errors. Thus, we analyze these reported errors directly, rather than attempting to back out inflation and population effects, which are not reported. We also calculate growth using equation [1] from reported and projected GDP (or GNP) values.

\section{Appendix B: Supplemental figures and tables}

The supplemental figures and tables below show and describe sensitivity analyses on the main analyses (Figs. 1-5). The captions describe the specifics of these analyses. 


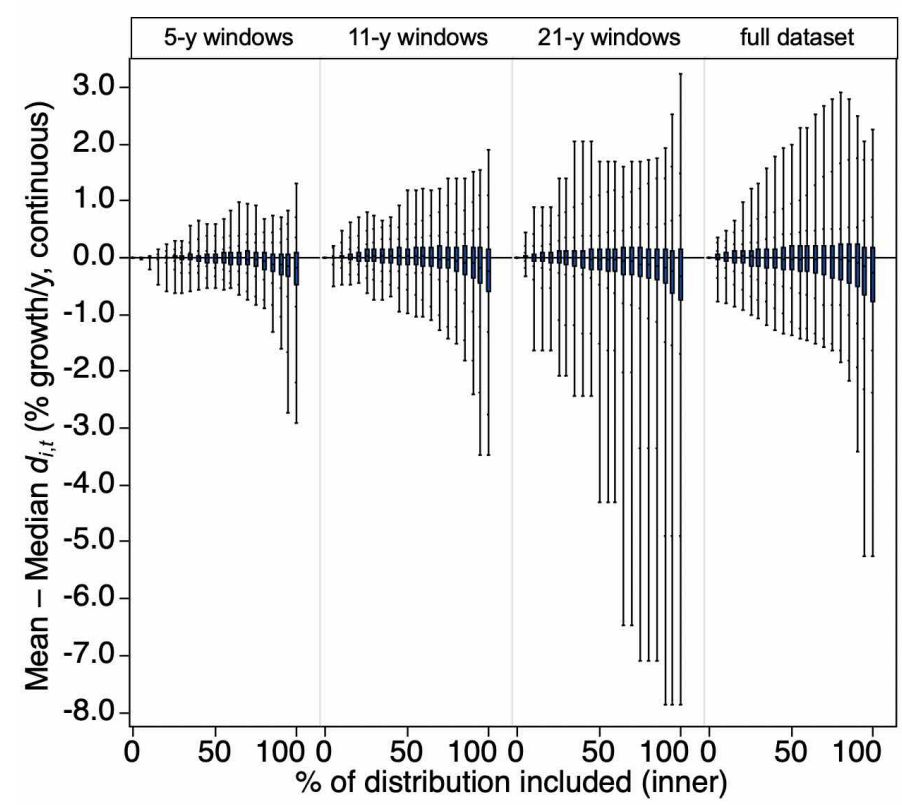

Figure B1: Sensitivity analysis on Fig. 2A, using different moving window sizes.
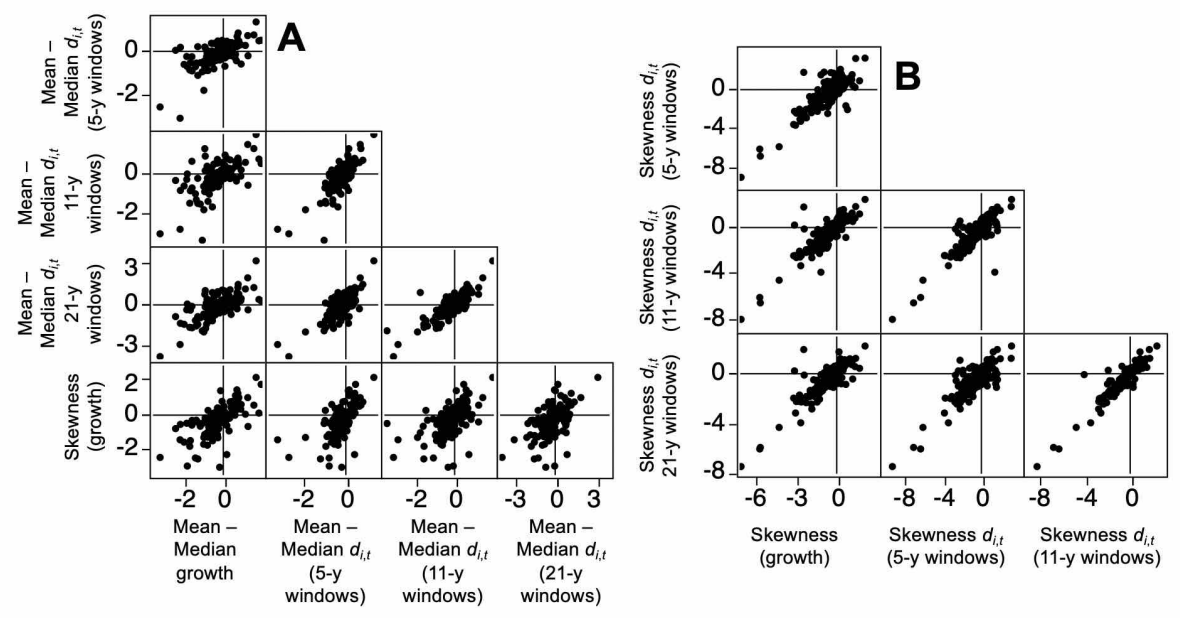

Figure B2: Correlations between possible measures of skewness: (A) focuses on differences between mean and median growth rates; (B) focuses on measures of Pearson skewness in growth rates. 

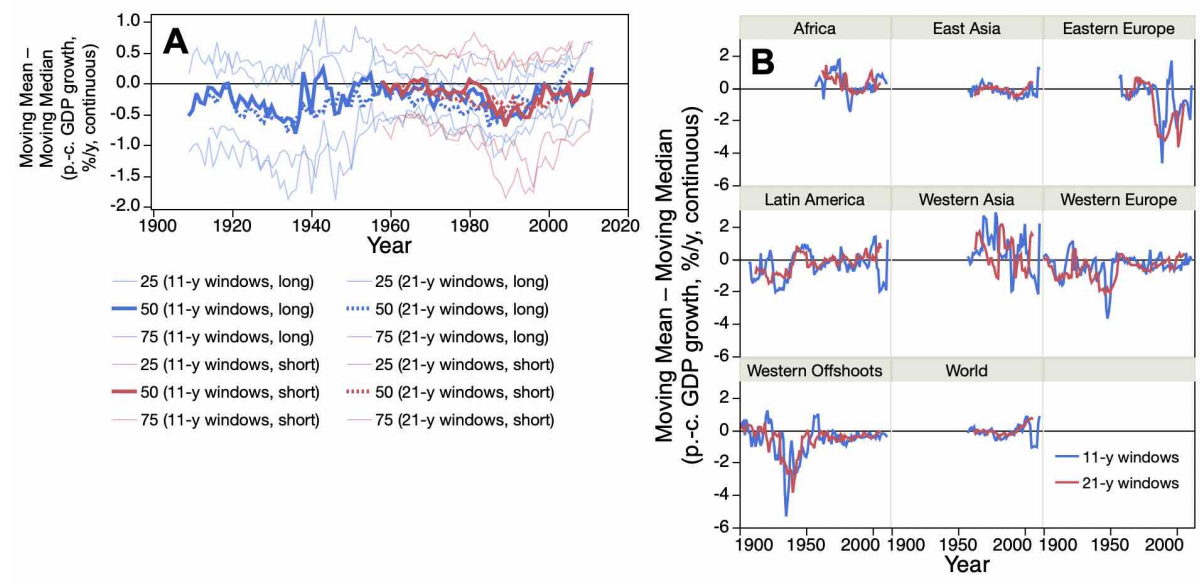

Figure B3: Sensitivity analysis on Fig. 1B, C, examining the effect of using 21-year moving windows instead of 11-year moving windows.
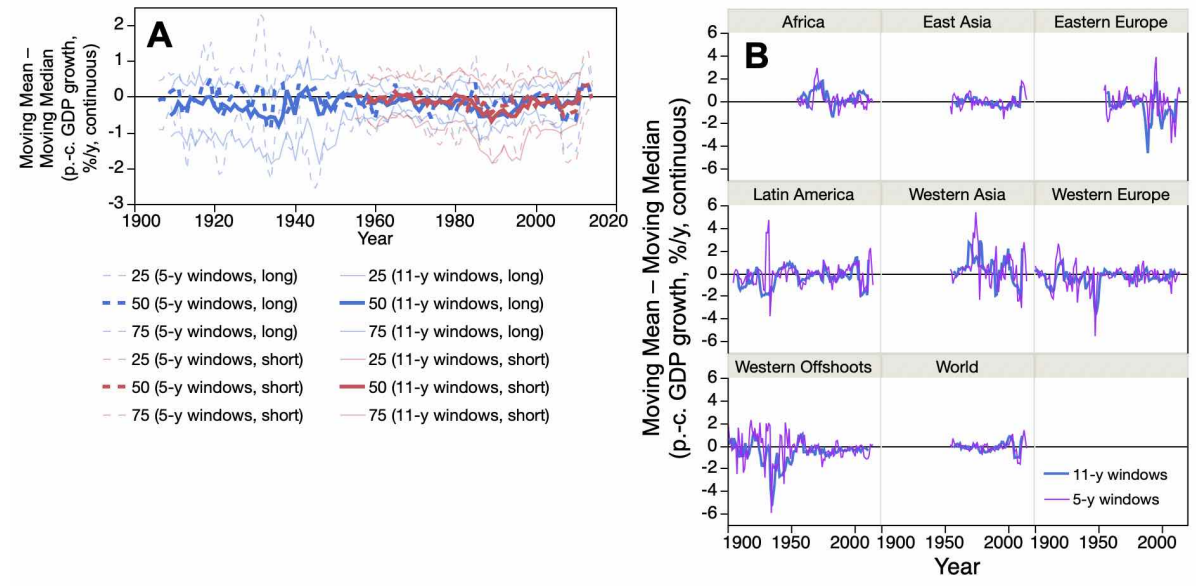

Figure B4: Sensitivity analysis on Fig. 1B, C, examining the effect of using 5-year moving windows instead of 11-year moving windows. 


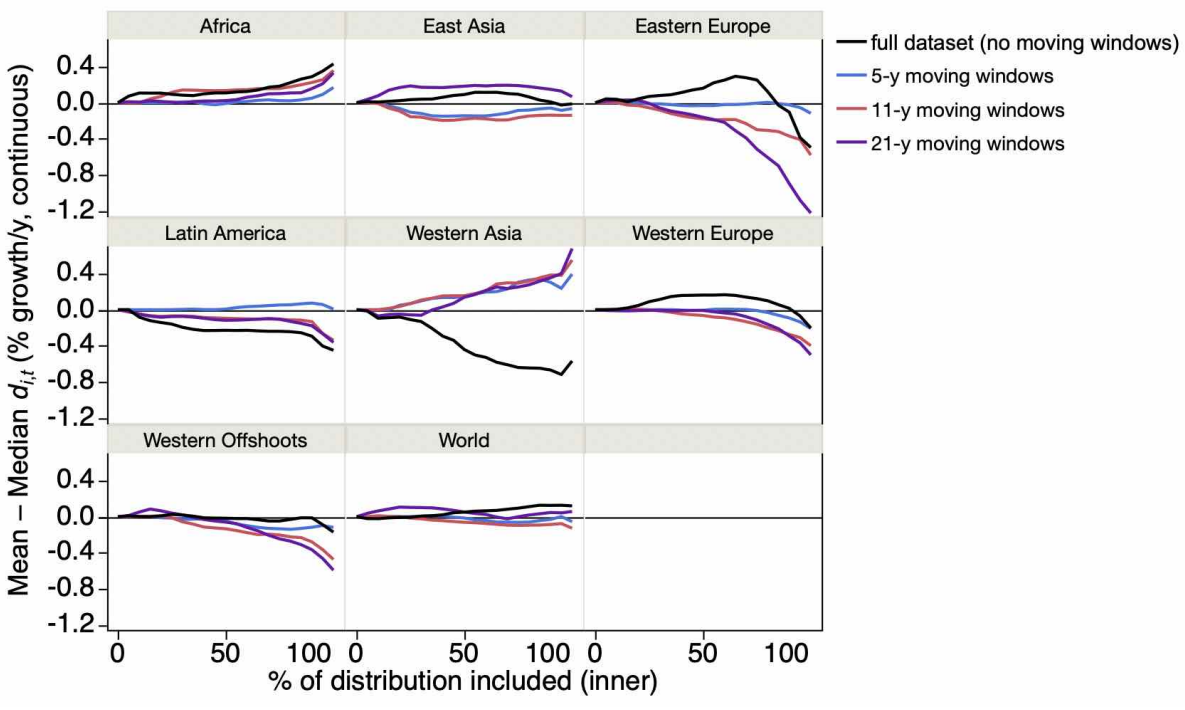

Figure B5: Sensitivity analysis on Fig. 2B, using different moving window sizes.

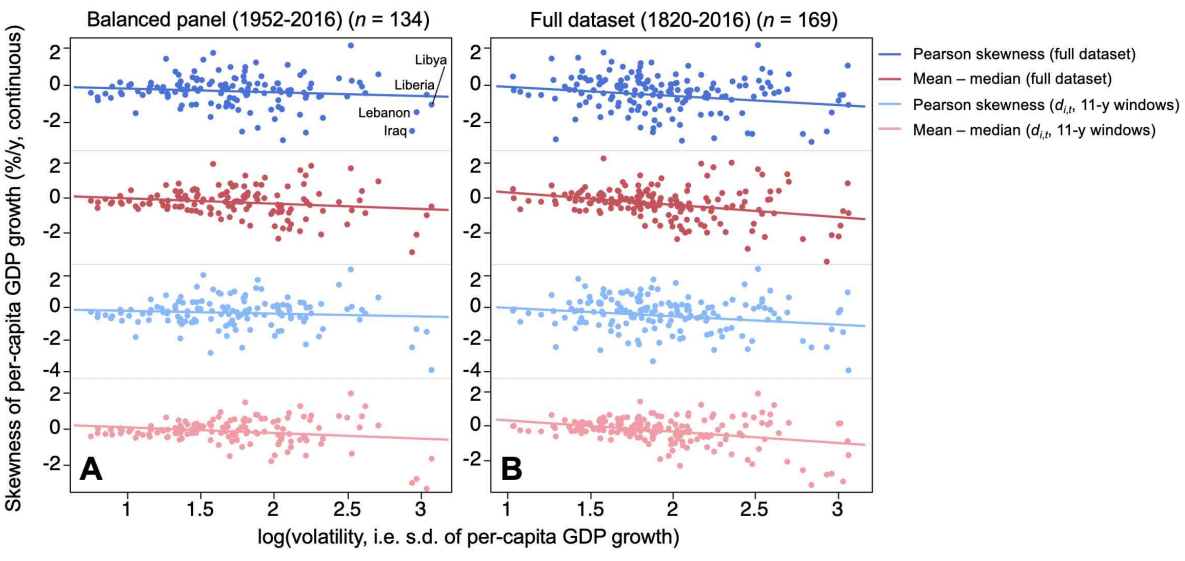

Figure B6: Correlation plots comparing relationships between several measures of growth skewness and volatility, in cross-sectional data (lines show OLS fits). Each point represents one country. Panel A shows measures from only 1952-2016, and only countries having data in each of those years. Panel B shows all countries and all years, allowing each country to have different time-series lengths. Countries highlighted in the top of panel $\mathrm{A}$ are countries with relatively high volatility and negative skewness, which were not included in the dataset of Bekaert \& Popov (2019). 
Table B1: Cross-sectional analysis (OLS) of partial correlations between mean - median $d_{i, t}$ (using 11-y windows) (our measure of skewness) and covariates. Volatility here refers to the standard deviation of per-capita GDP growth across the time series. Each column represents the lowest AICc model having the number of effects (in addition to the intercept) listed in the top row, among all possible models including covariates shown in Fig. 3 and their interactions. Only countries with annual data from 1952-2016 are included in this analysis $(n=134)$

\begin{tabular}{|c|c|c|c|c|c|}
\hline $\begin{array}{l}\text { Effect/number of } \\
\text { explanatory vari- } \\
\text { ables }\end{array}$ & 1 & 2 & 3 & 4 & 5 \\
\hline $\log ($ volatility $)$ & - & $\begin{array}{l}-0.27 \\
(0.12)^{* *}\end{array}$ & $\begin{array}{l}-0.38 \\
(0.12)^{* * *}\end{array}$ & $\begin{array}{l}-0.42 \\
(0.13)^{* * *}\end{array}$ & $\begin{array}{l}-0.41 \\
(0.13)^{* * *}\end{array}$ \\
\hline $\log (1952$ p.-c. GDP $)$ & - & - & $\begin{array}{l}-0.19 \\
(0.074) * * *\end{array}$ & $\begin{array}{l}-0.20 \\
(0.074) * * *\end{array}$ & $\begin{array}{l}-0.21 \\
(0.074) * * *\end{array}$ \\
\hline $\begin{array}{l}\text { mean(p.-c. } \\
\text { GDP growth) x } \\
\log (\text { volatility) }\end{array}$ & $\begin{array}{l}0.45 \\
(0.092) * * *\end{array}$ & $\begin{array}{l}0.44 \\
(0.091) * * *\end{array}$ & $\begin{array}{l}0.41 \\
(0.089)^{* * *}\end{array}$ & $\begin{array}{l}0.34 \\
(0.099)^{* * *}\end{array}$ & $\begin{array}{l}0.32 \\
(0.10)^{* * *}\end{array}$ \\
\hline $\begin{array}{lr}\text { mean(p.-c. } & \text { GDP } \\
\text { growth) x } & \log (1952 \\
\text { population) } & \end{array}$ & - & - & - & $\begin{array}{l}-0.046 \\
(0.029)\end{array}$ & $\begin{array}{l}-0.061 \\
(0.031)^{* *}\end{array}$ \\
\hline $\begin{array}{l}\text { mean(population } \\
\text { growth) x } \log (1952 \\
\text { population) }\end{array}$ & - & - & - & - & $\begin{array}{l}-0.052 \\
(0.037)\end{array}$ \\
\hline$n, R^{2}, \mathrm{AICc}$ & $\begin{array}{ll}134, & 0.16, \\
284 & \end{array}$ & $\begin{array}{ll}134, & 0.19, \\
281 & \end{array}$ & $\begin{array}{ll}134, & 0.22, \\
276 & \end{array}$ & $\begin{array}{ll}134, & 0.24, \\
275 & \end{array}$ & $\begin{array}{ll}134, & 0.25 \\
276 & \end{array}$ \\
\hline
\end{tabular}

standard errors in parentheses. ${ }^{*} p<0.1,{ }^{* *} p<0.05,{ }^{* * *} p<0.01$

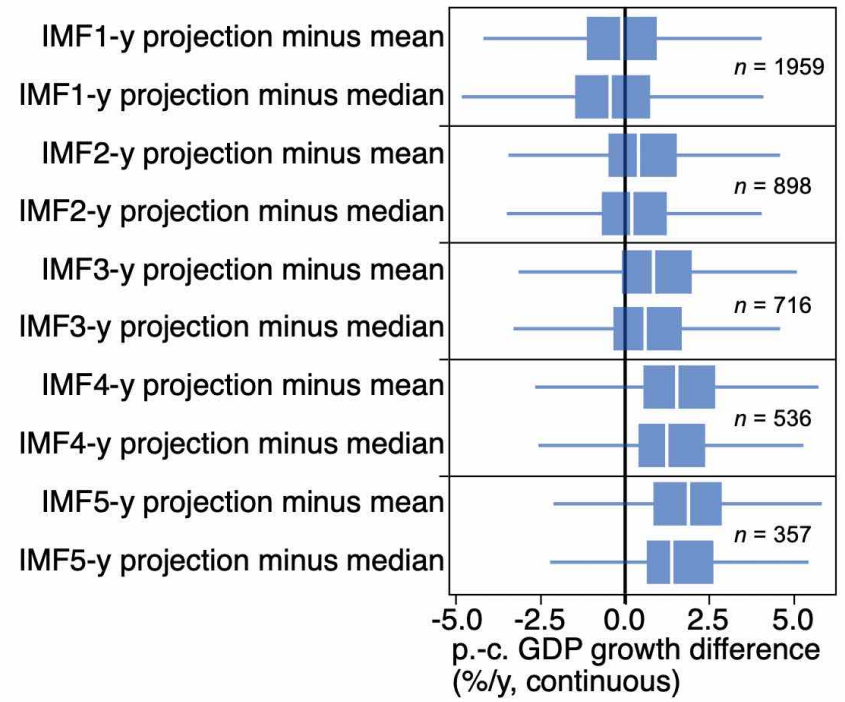

Figure B7: Comparisons between IMF projections of per-capita GDP growth and moving means or medians of observations (using 11-y windows). 
Table B2: Panel analysis (linear models) of partial correlations between mean - median percapita GDP growth (on 10-year intervals) and covariates. Following Bekaert \& Popov (2019) (BP), we obtain a panel by dividing the dataset into non-overlapping 10-year segments (1956-1965,..., 20062015). Volatility here refers to the standard deviation of per-capita GDP growth across the time series. Lag refers to a one-period (10-year) lag. Models are selected as follows: Model (1): based on BP table 4 model 2. Model (2): based on BP table 4 model 4 . Model (3): based on BP table 4 model 9 (with annual data and full sample). Model (4): model with same effects as Model 5 in Table B1 above, with no fixed effects. Model (5): model with same effects as Model 5 in Table B1 above, with country and time-period fixed effects. Model (6): minimum AICc model with country and time period fixed effects and 5 effects or fewer, among all possible models including the following covariates and/or their interactions: lag(mean - median p.-c. GDP growth, \%/y continuous), $\log$ (volatility), mean(p.-c. GDP growth), mean(population growth), log(p.-c. GDP, beginning of $10-y$ period), $\log$ (population, beginning of 10 -y period). Interaction effects are included in the model with global means subtracted from each interacted variable. Only countries with annual data from 1956-2015 are included in this analysis (134 countries).

\begin{tabular}{|c|c|c|c|c|c|c|}
\hline Effect/Model & (1) & (2) & (3) & $(4)$ & $(5)$ & (6) \\
\hline $\log ($ volatility) & $\begin{array}{l}-0.44 \\
(0.10) * * *\end{array}$ & $\begin{array}{l}-0.66 \\
(0.14) * * *\end{array}$ & $\begin{array}{l}-0.53 \\
(0.11) * * *\end{array}$ & $\begin{array}{l}-0.23 \\
(0.072) * * *\end{array}$ & $\begin{array}{l}-0.35 \\
(0.10) * * *\end{array}$ & - \\
\hline $\begin{array}{l}\text { lag(mean }- \text { median } \\
\text { p.-c. GDP growth, } \\
\% / y \text { continuous })\end{array}$ & - & $\begin{array}{l}-0.24 \\
(0.047) * * *\end{array}$ & - & - & - & $\begin{array}{l}-0.33 \\
(0.051) * * *\end{array}$ \\
\hline $\begin{array}{l}\log (\mathrm{p} .-\mathrm{c} . \\
\text { ginning of } 10-y \text { pe- } \\
\text { riod) }\end{array}$ & - & - & $\begin{array}{l}-0.031 \\
(0.15)\end{array}$ & $\begin{array}{l}-0.065 \\
(0.043)\end{array}$ & $0.12(0.14)$ & - \\
\hline $\begin{array}{l}\log (\text { p.-c. GDP, be- } \\
\text { ginning of } 10-y \text { pe- } \\
\text { riod) } x \log (\text { volatility })\end{array}$ & - & - & $\begin{array}{l}-0.20 \\
(0.083) * *\end{array}$ & - & - & - \\
\hline $\begin{array}{l}\text { mean(p.-c. } \\
\text { GDP growth) } \quad \mathrm{x} \\
\log (\text { volatility })\end{array}$ & - & - & - & $\begin{array}{l}0.16 \\
(0.016) * * *\end{array}$ & $\begin{array}{l}0.15 \\
(0.017)^{* * * *}\end{array}$ & $\begin{array}{l}0.23 \\
(0.018)^{* * *}\end{array}$ \\
\hline $\begin{array}{l}\text { mean(p.-c. } \\
\text { GDP growth) } \mathrm{x} \\
\log (\text { population, } \\
\text { beginning of } 10-\mathrm{y} \\
\text { period) }\end{array}$ & - & - & - & $\begin{array}{l}-0.017 \\
(0.0093)^{*}\end{array}$ & $\begin{array}{l}-0.017 \\
(0.010)^{*}\end{array}$ & - \\
\hline $\begin{array}{l}\text { mean(population } \\
\text { growth) } \\
\log (\text { population, } \\
\text { beginning of } 10-y \\
\text { period) }\end{array}$ & - & - & - & $\begin{array}{l}-0.035 \\
(0.024)\end{array}$ & $\begin{array}{l}-0.035 \\
(0.039)\end{array}$ & - \\
\hline $\begin{array}{l}\text { mean(p.-c. } \\
\text { GDP growth) } x \\
\text { mean(population } \\
\text { growth) }\end{array}$ & - & - & - & - & - & $\begin{array}{l}-0.052 \\
(0.012)^{* * *}\end{array}$ \\
\hline $\begin{array}{l}\log (\text { volatility }) \\
\operatorname{lag}(\text { mean }- \text { median } \\
\text { p.-c. GDP growth, } \\
\% / y \text { continuous })\end{array}$ & - & - & - & - & - & $\begin{array}{l}0.22 \\
(0.051)^{* * *}\end{array}$ \\
\hline $\begin{array}{l}\log (\mathrm{p} .-\mathrm{c} . \\
\text { ginning of } 10-y \text { pe- } \\
\text { riod) x lag(mean - } \\
\text { median p.-c. GDP } \\
\text { growth, \%/y contin- } \\
\text { uous) }\end{array}$ & - & - & - & - & - & $\begin{array}{l}-0.13 \\
(0.030) * * *\end{array}$ \\
\hline $\begin{array}{l}\text { Country and time- } \\
\text { period fixed effects }\end{array}$ & $\mathrm{Y}$ & $\mathrm{Y}$ & $\mathrm{Y}$ & $\mathrm{N}$ & $\bar{Y}$ & $\mathrm{Y}$ \\
\hline $\begin{array}{l}n, \text { number of coun- } \\
\text { tries, } R^{2}\end{array}$ & $\begin{array}{l}804, \quad 134, \\
0.23\end{array}$ & $\begin{array}{ll}670, & 134, \\
0.29 & \end{array}$ & $\begin{array}{l}804, \quad 134, \\
0.17\end{array}$ & $\begin{array}{l}804, \quad 134, \\
0.17\end{array}$ & $\begin{array}{l}804, \quad 134, \\
0.34\end{array}$ & $\begin{array}{l}670, \quad 134, \\
0.44\end{array}$ \\
\hline
\end{tabular}

standard errors in parentheses. ${ }^{*} p<0.1,{ }^{* *} p<0.05,{ }^{* * *} p<0.01$ 

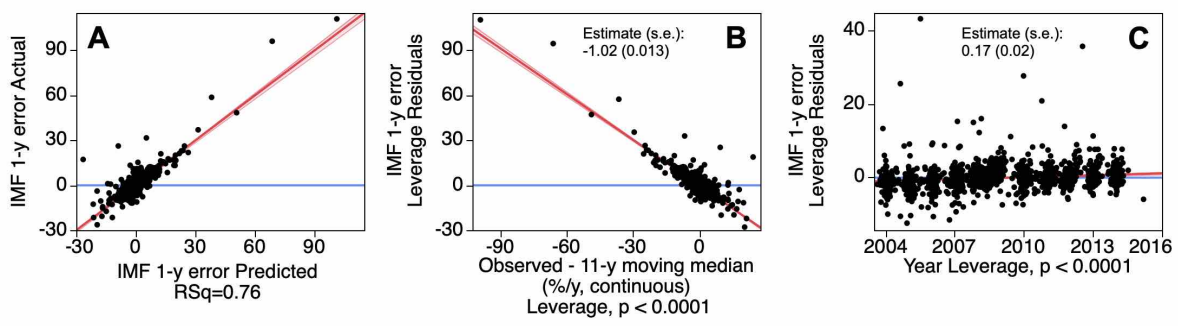

Figure B8: Panel analysis (leverage plots, from an OLS model) of partial correlations between IMF projection errors in per-capita GDP growth projected one year ahead and each of: the difference between observed growth and the 11-y moving median (i.e. the median of the current year, the five previous years, and the five subsequent years), $d_{i, t}(\mathrm{~B})$, and year (C). Per-capita GDP (not shown as a covariate) was not partially correlated with these projection errors. Data are annual (2004-2014) for 195 countries $(n=1959)$.
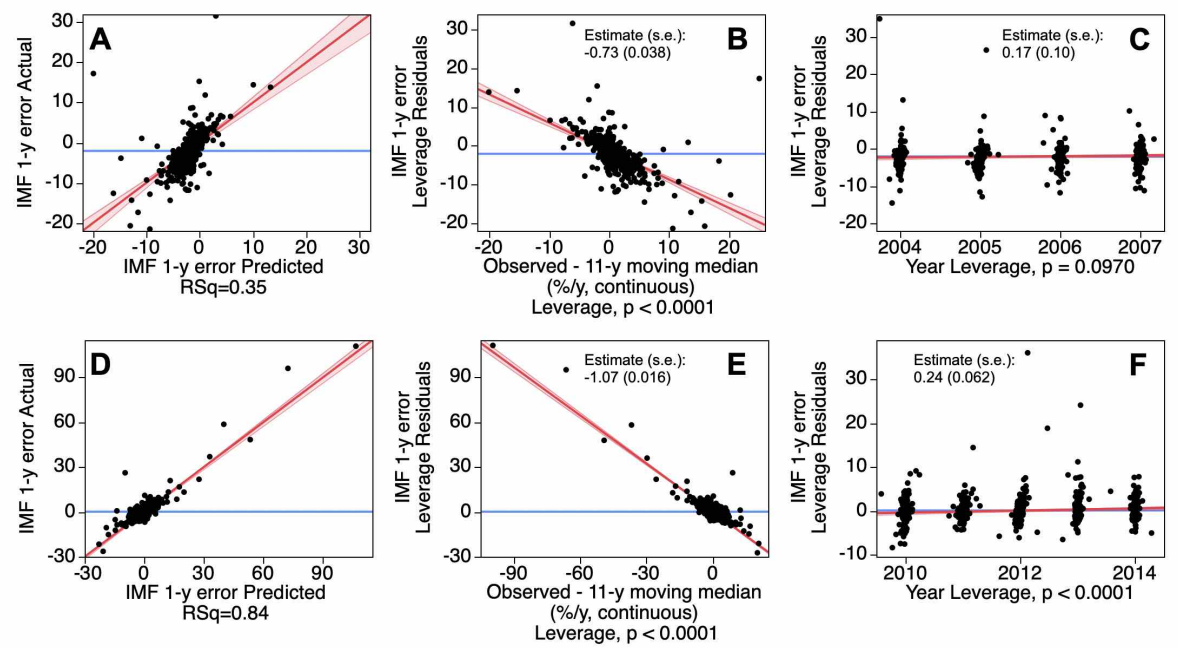

Figure B9: Panel analysis of Fig. B8 above, repeated separately for time periods before (A-C) and after 2008-2009 (D-F) analyzed separately.

Table B3: Summary of panel analysis of IMF projection errors, similar to Fig. B9, but for longer projection horizons.

\begin{tabular}{|c|c|c|c|c|}
\hline Effect/Response & $\begin{array}{lr}\text { IMF } & 2-y \\
\text { error }(\% / y, \\
\text { continuous) }\end{array}$ & $\begin{array}{l}\text { IMF } \quad 3-y \\
\text { error }(\% / y, \\
\text { continuous) }\end{array}$ & $\begin{array}{l}\text { IMF } \quad 4-y \\
\text { error (\%/y, } \\
\text { continuous) }\end{array}$ & $\begin{array}{lr}\text { IMF } & 5-y \\
\text { error }(\% / y, \\
\text { continuous) }\end{array}$ \\
\hline $\begin{array}{l}\text { Observed }-11-\mathrm{y} \text { moving } \\
\text { median (\%/y, continuous) }\end{array}$ & $\begin{array}{l}-1.03 \\
(0.011)^{* * *}\end{array}$ & $\begin{array}{l}-1.03 \\
(0.013) * * *\end{array}$ & $\begin{array}{l}-1.02 \\
(0.015)^{* * *}\end{array}$ & $\begin{array}{l}-1.14 \\
(0.019)^{* * *}\end{array}$ \\
\hline Year & $\begin{array}{l}-0.15 \\
(0.049) * * *\end{array}$ & $\begin{array}{l}-0.30 \\
(0.072)^{* * *}\end{array}$ & $-0.21(0.12)^{*}$ & $-0.27(0.21)$ \\
\hline$n, R^{2}$ & $898,0.90$ & $716,0.90$ & $536,0.89$ & $357,0.91$ \\
\hline
\end{tabular}



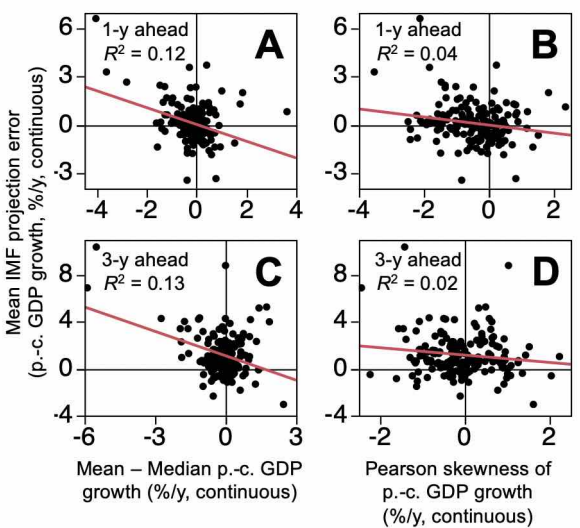

Figure B10: Comparison of results shown in Fig. 4B,C-reproduced here in panels A and C-to comparable results with Pearson skewness as a measure (panels B and D), instead of the difference between mean and median per-capita GDP growth. Each point represents one country $(n=164$ in $\mathrm{A}, \mathrm{B}, n=175$ in $\mathrm{C}, \mathrm{D})$. OLS fits, including an intercept, are shown (red lines). Negative slopes are statistically significant in panels $\mathrm{A}-\mathrm{C}$, with $p<0.001$ in panels $\mathrm{A}$ and $\mathrm{C}$, and $p=0.015$ in panel B $(p=0.063$ in panel D). Positive intercept is statistically significant in panels $\mathrm{C}$ and $\mathrm{D}$, with $p<0.001$.
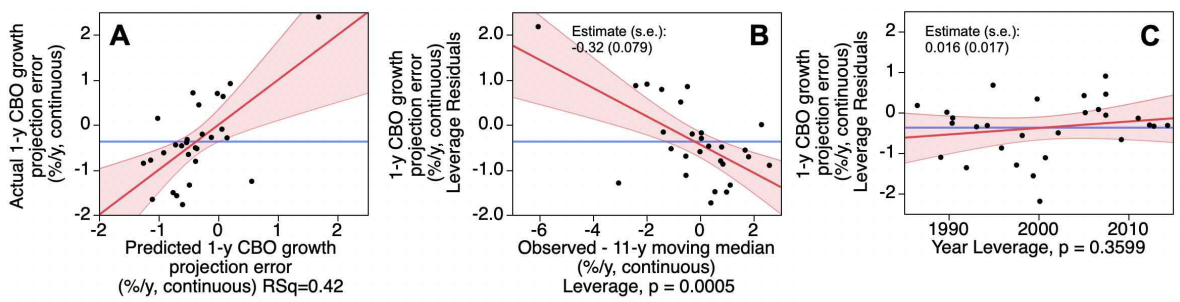

Figure B11: Panel analysis of CBO's projection errors of nominal GDP growth, analogous to Fig. B8.

Table B4: Summary of panel analysis of CBO projection errors, similar to Fig. B11, but for longer projection horizons.

\begin{tabular}{l|l|l|l|l|l}
\hline Effect/Response & $\begin{array}{l}\text { CBO 2-y } \\
\text { error (\%/y, } \\
\text { continu- } \\
\text { ous) }\end{array}$ & $\begin{array}{l}\text { CBO 3-y } \\
\text { error (\%/y, } \\
\text { continu- } \\
\text { ous) }\end{array}$ & $\begin{array}{l}\text { CBO 4-y } \\
\text { error (\%/y, } \\
\text { continu- } \\
\text { ous) }\end{array}$ & $\begin{array}{l}\text { CBO 5-y } \\
\text { error (\%/y, } \\
\text { continu- } \\
\text { ous) }\end{array}$ & $\begin{array}{l}\text { CBO 6-y } \\
\text { error (\%/y, } \\
\text { continu- } \\
\text { ous) }\end{array}$ \\
\hline $\begin{array}{l}\text { Observed - 11-y moving } \\
\text { median (\%/y, continuous) }\end{array}$ & $\begin{array}{l}-1.08 \\
(0.15)^{* * *}\end{array}$ & $\begin{array}{l}-1.19 \\
(0.33)^{* * *}\end{array}$ & $-0.78(0.48)$ & $-0.37(0.57)$ & $-0.43(0.69)$ \\
\hline Year & -0.018 & $\begin{array}{l}0.0019 \\
(0.072)\end{array}$ & $0.048(0.10)$ & $0.089(0.12)$ & $0.0087(0.15)$ \\
\hline$n, R^{2}$ & $(0.032)$ & $28,0.29$ & $28,0.11$ & $28,0.042$ & $28,0.016$ \\
\hline
\end{tabular}

